\title{
Perceptions about prenatal care: views of urban vulnerable groups
} Renee Milligan1, Barbara K Wingrove*2, Leslie Richards3, Margaret Rodan ${ }^{4}$, Lillie Monroe-Lord ${ }^{5}$, Velishie Jackson
Cassandra Henderson ${ }^{2}$ and Allan A Johnson Hatcher

Address: ${ }^{1}$ School of Nursing and health studies, Georgetown University, Washington, D.C, ${ }^{2}$ Division of Epidemiology, Statistics \& Prevention Research, National Institute of Child Health and Human Development, Rockville, MD, ${ }^{3}$ Department of Sociology, University of the District of Columbia, Washington, D.C, USA, ${ }^{4}$ Department of Family Medicine, Georgetown University, Washington, D.C, ${ }^{5}$ Community Extension Service, University of the District of Columbia, Washington, D.C, 'epartment of Obstetrics and Gynecology, Georgetown University, Washington, D.C, ${ }^{7}$ American Public Health Association, Washington, D.C and ${ }^{8}$ Allied School of Nutrition, Howard University, Washington, D.C

E-mail: Renee Milligan - TWORAMS@aol.com; Barbara K Wingrove* - B.Wingrove@nih.gov; Leslie Richards - Gladmar@erols.com; Margaret Rodan - rodanm@georgetown.edu; Lillie Monroe-Lord - LMonroeLord@udc.edu; Velishie Jackson - vaj@georgetown.edu; Barbara Hatcher - barbara.hatcher@apha.org; Cynthia Harris - Cynthia.Harris@worldnet.att.net; Cassandra Henderson - cehenderson@micmhra.org; Allan A Johnson - AJohnson@Fac.Howard.edu

${ }^{*}$ Corresponding author

Published: 6 November 2002

Received: 21 May 2002

BMC Public Health 2002, 2:25

This article is available from: http://www.biomedcentral.com/I47I-2458/2/25

(c) 2002 Milligan et al; licensee BioMed Central Ltd. This is an Open Access article: verbatim copying and redistribution of this article are permitted in all media for any purpose, provided this notice is preserved along with the article's original URL.

\begin{abstract}
Background: In the United States, infant mortality rates remain more than twice as high for African Americans as compared to other racial groups. Lack of adherence to prenatal care schedules in vulnerable, hard to reach, urban, poor women is associated with high infant mortality, particularly for women who abuse substances, are homeless, or live in communities having high poverty and high infant mortality. This issue is of concern to the women, their partners, and members of their communities. Because they are not part of the system, these womens' views are often not included in other studies.
\end{abstract}

Methods: This qualitative study used focus groups with four distinct categories of people, to collect observations about prenatal care from various perspectives. The 169 subjects included homeless women; women with current or history of substance abuse; significant others of homeless women; and residents of a community with high infant mortality and poverty indices, and low incidence of adequate prenatal care. A process of coding and recoding using Ethnograph and counting ensured reliability and validity of the process of theme identification.

Results: Barriers and motivators to prenatal care were identified in focus groups. Pervasive issues identified were drug lifestyle, negative attitudes of health care providers and staff, and non-inclusion of male partners in the prenatal experience.

Conclusions: Designing prenatal care relevant to vulnerable women in urban communities takes creativity, thoughtfulness, and sensitivity. System changes recommended include increased attention to substance abuse treatment/prenatal care interaction, focus on provider/staff attitudes, and commitment to inclusion of male partners. 


\section{Background}

In the United States, infant mortality rates remain more than twice as high for African Americans as compared to other racial groups, such as non-Hispanic Whites, Hispanics, and Asians/Pacific Islanders [1]. Two of the objectives for Healthy People 2000 and 2010 are to eliminate the racial disparities in infant mortality and increase participation in prenatal care, particularly for African-Americans $[2,3]$.

In 1998, Washington D.C. (D.C.), a primarily African American urban community, reported significantly higher infant mortality rate than the national averages; in fact, the highest rate of infant deaths compared to any state in the United States (13.8 infant deaths/1000 live births in 1998, almost twice the national rate of 7.2) [1]. In addition, Black infant mortality in 1998 in D.C. was four times higher than for Whites (17.2 vs. 4.3 infant deaths/1000 live births respectively) [1]. Although decreasing each year, the infant mortality disparity in D.C. remains [4].

Prenatal provider practice is built on the notion that early and regular care, according to the American College of Obstetrics and Gynecology (ACOG) schedules [5] is important. The relationship of prenatal care (PNC) to lower infant mortality in general may be controversial [6-11], but in populations at high medical and social risk, such as minority women residing in D.C., comparatively low PNC utilization and high infant mortality coexist, and are potentially related.

Nationally, fewer African American women enter prenatal care (PNC) beginning in the first trimester as compared to White women $(73.3 \%$ and $87.9 \%$ respectively in 1998$)$ [1]. The disparity is even greater in D.C. (67.1\% and $90.9 \%$ respectively in 1999) [12]. Minority women from poor urban communities, such as D. C., enter prenatal care later and have fewer prenatal care visits than white women of higher socio-economic levels [13,14]. Women who make little or no use of prenatal care often are disenfranchised members of the community, such as homeless and substance abusing women $[15,16]$. In D.C., many people, particularly those from disenfranchised commu- nities, do not believe that prenatal care is important. [14,17-21]. Further, although there is no mandatory reporting of drug use during pregnancy in D.C., drug dependent women exhibit late prenatal care initiation and less utilization [4].

Prior studies have sought to understand the reasons for poor prenatal care utilization among disenfranchised women. Documented barriers to prenatal care among similar populations include: 1) previous, unsatisfying experiences with prenatal services including culturally inappropriate care $[14,16,20-23]$; 2) unplanned or denied pregnancy $[14,24-26] ; 3)$ avoidance of sanctions for poor health habits such as drug and alcohol use, risky sexual behaviors, heavy smoking, and eating disorders $[14,22,27-30] ; 4)$ stress or depression [14,31-33]; 5) homelessness $[14,16,34,35] ; 6)$ poor treatment in the system due to race, particularly for African Americans [23,33,36-39]; 7) beliefs about the importance of initiation and compliance with prenatal care [26,37]; and 8) financial issues $[27,38,39]$. While we understand some of the barriers, health care providers need to better understand what attracts vulnerable urban women to and retains them in prenatal care.[23,26,32,37,40,41]. To address issues related to initiation and compliance with prenatal care, and its association with infant mortality in D.C, the National Institutes of Health (NIH) National Institute of Child Health and Human Development (NICHD) and the NIH Office of Research on Minority Health (ORMH) sponsored this study of barriers and motivators of prenatal care as identified by vulnerable, hard to reach populations. The study reported here includes current and retrospective observances about prenatal care obtained through focus group methodology.

\section{Methods}

The research questions guiding this study were as follows:

From the perspective of vulnerable groups:

(1) What are the barriers of prenatal care for vulnerable women in D.C.?

Table I: Characteristics of Total Sample Participants

\begin{tabular}{lll}
\hline Gender: & Female & $73 \%$ \\
Income & Below $\$ 2500$ per year & $54 \%$ \\
Education & High School Graduates & $63 \%$ \\
Mean Age: & Childbearing age women & 33 (range 17 to 50) \\
& Male significant others & 46 (range 20 to 53) \\
& Grandmothers & 59 (range 4l to 87) \\
& Community leaders & 47 (range 33 to 64)
\end{tabular}


(2) What changes will help vulnerable women overcome barriers and be motivated to initiate and use prenatal care?

Barriers were defined as any states, conditions or events that make it difficult or prevents a woman from freely and successfully obtaining prenatal care. Motivators were defined as internal factors that cause a woman to seek and attain prenatal care or those factors external to the individual that enhance opportunity for prenatal care. System was defined as the institutions and agencies established to deal with the individual on behalf of society [42].

Focus group methodology was chosen to allow the investigators to hear the voices of vulnerable groups $[43,44]$. As opposed to one-to-one, face-to-face interviews, focus groups offered a way to "listen to" and "learn from" the plural voices of people in a safe and neutral environment [44]. The focus groups helped the researchers connect the voices and stories of participants to previously reported quantitative findings about barriers to care, as well as identify those areas that can be highlighted through qualitative methodology [43-46]. The research team understood that focus group findings would not be generalizable; however, focus group methodology was accepted as an important way to learn the social meaning of prenatal care in targeted communities where many babies died each year, through hearing communities' and vulnerable women's authentic voices.

\section{Focus groups}

Eighteen focus groups were conducted. There were four types, each conducted with at least 4 groups to allow participant comments to reach saturation (the process of ceasing to encounter new information on the topic [45]). Participants were identified through care center representatives, community activists, and shelter administrators. Five groups were conducted with homeless childbearing age women (hereafter referred to as homeless women focus groups). Four were conducted with childbearing aged women with a history of substance abuse (hereafter referred to as drug-dependent women focus groups). Four were conducted with male significant others of homeless, childbearing age women (hereafter referred to as male significant others focus groups). Five were conducted with members of a community with high infant mortality and poverty indices, and low incidence of adequate prenatal care [4](hereafter referred to as community focus groups). Each focus group in the community had specific types of participants: pregnant and postpartum women (two focus groups), grandmothers (one focus group), community leaders (one focus group) and men who had fathered at least one child and were currently partners of child bearing age women (one focus group). Prior to conducting focus groups, the study had IRB clearance from all participating institutions and all researchers were trained in focus group methodology.

\section{Sample description}

The findings represent the views of 169 people with characteristics as presented in Table 1. The participants tended to be older since participants were purposively chosen for experience with the system and for characteristics (drugdependence, homelessness) that develop over time. Teenagers were not excluded.

The four general types of focus groups each comprised approximately one-fourth of the sample. The community focus groups (totalparticipants $\mathrm{n}=34$ ), conducted in community sites, included pregnant and postpartum women $(n=13)$, grandmothers $(n=6)$, community leaders $(n=10)$, and male partners of childbearing age women $(n=5)$. The drug-dependent women focus groups, conducted in shelters or treatment facilities, included pregnant and postpartum women $(n=33)$ and women of childbearing age $(n=12)$. The homeless women focus groups, conducted in shelters, included pregnant and postpartum women $(\mathrm{n}=29)$ and women of childbearing age with at least one child $(\mathrm{n}=22)$. The male significant other focus groups included 39 men.

\section{Focus group description}

Prior to conducting focus groups, issues related to access to prenatal care were identified from literature review and expert opinion. An overall guide was developed, which included the following questions (minimally adjusted by type of group).

What do people (in D. C./in your community/with your lifestyle) do to keep themselves and their children healthy?

When I say prenatal care, what do you think of?

Many people find it difficult at least some of the time to keep their prenatal care appointments. What barriers might prevent a woman from receiving prenatal care in the District?

What motivates women to start and keep getting prenatal care?

What kind of help would encourage women (in the District/in your community/with your lifestyle) to get prenatal care?

So that focus groups were as consistent as possible, specific probes and follow-up questions were included in the script. 
Focus groups were conducted by teams that included African-American and White women and men. There was racial diversity in each team, which consisted of a trained moderator, assistant moderator and note taker/administrator. For the two-hour focus groups, participants were given $\$ 25$ as reimbursement for their time. Although childcare was available; occasionally children were present. All focus group responses were audiotape recorded and transcribed.

When the groups met, the moderator, assistant moderator, and note taker welcomed and oriented the subjects individually, and obtained informed consent. The moderator presented ground rules to the participants, and discussed the purpose of the study as to solicit their views of prenatal care. Assurances were given that all opinions were welcomed, no answer was right or wrong and that all comments would remain anonymous and confidential.

\section{Analyzing and validating data}

As focus groups were completed, qualitative analysis proceeded using an evaluative approach [46] with emphasis on counting to enhance validity [47]. Data were transcribed verbatim by outside transcribers. Only minor editorial changes were made to ensure accuracy of example quotes. Subject identifiers were eliminated. Data were read and organized into beginning themes with no limitations put on numbers of themes. Themes were inductively identified that emerged from the data; then, codes were developed to represent them [46]. Ethnograph was used as a tool for data management $[47,48]$. Using Ethnograph, segments of data were coded and sorted by code, examined, recombined or collapsed.

After coding, the research team chose the themes that indicated possible system reform. The approach to reform was through organizational change, as defined as how to enhance human service organization effectiveness in relating to clients with a goal of increasing the effectiveness of the services provided to the client population served [49].

\section{Coding process}

The process of coding the data ensured a high degree of accuracy, agreement, and rigor, through coding and recoding to validate important issues [50]. Ten members of the research team (described as first level coders), were oriented to qualitative evaluative methods as advised by Patton [45], and assisted in identifying initial codes. Each transcript was first evaluated by two researchers, and then reevaluated by a specially trained team, focused on identifying codes representing frequently mentioned, relevant issues. Consistent with inductive analysis, the number of codes was expanded as each transcript was evaluated. Codes were added to the scheme as there was repetition (approximately 5 or more times). Further evaluation compared codes for consistency, completeness, and relevance to system change. To ensure inter-rater consistency, a final researcher recoded all documents using the developed coding scheme. Adjustments were made in the coding scheme when minor differences in interpretation were identified. The codes that emerged were further classified as barriers or motivators of prenatal care utilization. Coded transcripts were returned to researchers who conducted each type of focus group for final validation of codes.

Due to the richness of the data set, and to present a cogent discussion of the variety of codes that emerged, issues were prioritized. Using an approach suggested by Miles and Huberman [46], counting of final codes representing barriers and motivators was used to draw and verify conclusions. The codes representing the ten barriers and motivators that were identified most frequently in all groups were culled from the data and were compared across type of focus group. For this paper, using Shulman's definition of systems [43], the research barriers to or motivators of prenatal care related to systems, or organizational change. This approach was chosen because social, medical and educational systems may be hard to access for both individuals well equipped to handle them as well as those with limited education and resources [43]. The services established for people are often so complex that it is difficult for individuals to make use of them.

\section{Results}

\section{Views of the total sample}

Three themes that could indicate a need for systems change were pervasive across focus groups: drug lifestyle, role of baby's father, and staff/provider attitudes. These three general themes were mentioned as barriers to as well as potential motivators of care.

Frequently mentioned issues from all groups are presented, then exemplars and insights from specific types of focus groups are added. These exemplars provide a sense of the beliefs operating in vulnerable populations. Each barrier to prenatal care that is discussed was mentioned at least thirty-five times across at least nine focus groups. Each motivator of prenatal care discussed was mentioned at least sixteen times across seven focus groups.

\section{Theme one: drug lifestyle}

One of the pervasive themes apparent in all types of focus group was related to drug lifestyle. From community focus groups, this was the most frequent code representing a barrier to prenatal care. Women voiced that drug lifestyles delayed initiation of prenatal care. Women also feared that their provider would find out about current drug use. This was particularly poignant in community focus groups, as the sampling was not purposive for substance 
abusers; yet drug lifestyles were defining issues for the community. A community member summed it up in the following:

"Their priority is drugs, and the appointment is secondary."

In drug-dependent women focus groups, drug lifestyle was also the most frequently mentioned barrier to prenatal care. The drug lifestyle dominated any concern about having prenatal care. As one focus group participant put it:

"The fast life, just plain laziness, withdrawal symptoms"

prevented adherence to prenatal care.

Another said,

"Do you think that I'm going to look at my watch and say: 'it's nine o'clock everybody, so put down the [crack] pipe so I can go to my prenatal care appointment'?"

Another participant in the substance abusing women focus group summed it up as follows:

"I was using heroin and crack cocaine. What led me here (detox) was I was sick and tired of being sick and tired and I knew I could be a better parent to my children and I just was tired. I was fed up and I just couldn't take it no more. I was just worn out and I knew that my mother was a drug user and I knew that it kept her away from me and I knew how I felt by my grandmother raising me my whole entire life."

For homeless participants, the effect of drug use on the unborn child and the new baby was important. This concern is characterized in the following quotes:

"I was so far out, drugging and using, I had a son that was born, he was born at five months, he weighted $1 \mathrm{lb}$. and $8 \mathrm{oz}$. I had him at [hospital] and they were really looking for him to die because it was no way that he was suppose to survive that young. Thank the Lord that he did and now he is four years old now. He has a respiratory problem; he has to have a machine. So far he is doing okay. That was due to my addiction, not getting the proper prenatal care because I just drugged all the time."

"Just because the baby have all parts of their body, you still cannot tell whether you gonna affect that baby later on in life, that's what a lot of people fail to realize, you know they can have learning disabilities. "

"On TV I see these babies with the bottle in their mouth and I was drugging in my first month. I just started crying and I said: 'I can't do this to my child.' So I stopped. I just stopped. Every time I got pregnant I could stop drugging. Soon after I had that baby I just went right on back."

Significant others focus groups were also quite revealing about how the drug lifestyle was a barrier to prenatal care, as in the following quotes:

"And I was out there smoking crack. So I wasn't there for her and I blame myself for that because if I had been there, not saying that she wouldn't have had a miscarriage, but maybe I could have got her to the hospital. Maybe just being there to support. Maybe other women are experiencing that too. That the father of the unborn child is not around. Maybe they are worried that he don't care."

One aspect of drug lifestyle, prenatal care/drug treatment interaction, was mentioned as an important potential motivator. Prenatal care and drug treatment facilitated each other through interacting requirements that women in detoxification programs receive prenatal care, and women in prenatal care abusing drugs receive high priority referrals for detoxification centers/programs (detox). Participants noted that to receive a referral into drug treatment, one must first enter detox. However, according to focus group participants, if they were not currently drugging, they could not get detox treatment. Thus, to get into detox, participants reported using drugs before going for prenatal care, causing positive drug urine screens, resulting in priority detox referrals.

Theme two: role of baby's father

For all focus group participants, the most frequently mentioned motivator was the role of baby's father. When there was male involvement, there was a belief that the woman's overall condition improved. For example, one significant other focus group participant commented:

"When my girlfriend was pregnant [she] had to take care of this, take care of that, and she was smoking and drinking, and I was going behind her saying that's the wrong thing to be doing. Won't you do this. [In] certain ways I stood behind her [to] make sure she was doing the right things. [She] started going to programs and liking them. [You] must make sure that they make appointments on time and just spend the time..."

One significant other participant summed up the majority of the group's feelings when he said:

"... and the Black male, what we can do, is be the support unit for them, we could be a shoulder for them in a way where we could take them to their appointments if we have time, or we could be a sounding board for [them] if they have problems. If they're eating the wrong food, try to convince them to eat the right food, cause, not only are they carrying the babies themselves, if we're the father, it's our baby also. And if it's not our 
baby we still play a part, because it's part of our generation, so we'll be a community."

While the men strongly vocalized the need to support women, they admitted that their actual behavior could be a barrier to care. Two quotes significant others illustrate this:

1) "Let's not lose perspective here. Now we admit we have an obligation too. I'm saying that the women are out there too, but we as men have an obligation. We give these babies to these women. Why can't we take some time out and tell the woman what she needs to do, even though she may not listen. Why can't we say: 'give me the baby, I'll take it to the doctor?' "

2) "Some men are scared of responsibility so they are gonna say whatever they think could hurt the woman and, or mess the woman up to the point that it mess her and the baby up, make them wait or what have you. Scared of responsibility."

A grandmother participant of the community focus groups also voiced this issue, as in the following quote:

"...because there's a lot of children being born, that if born will never know their fathers, because they're killed. That's a setback for the mothers, then the mothers are going to be father and mother, and that's a strain. That's a strain on one person-a young person, too. No, don't be kind. Be blunt. Be to the point. How many of you still have that man? How many of you even see that man? How many of you even talk to him on the phone, even know where he is, if he's not in Lord's - most of em are in Lord's, you know that's in the cemetery. But the ones that are still alive, and not locked up, they're out there with some other dummy, pregnant, thinking the same thing that you're thinking. "

Further, a community leader said:

"And somebody's going to have to sit up some place in an auditorium, in a school, and ask the pertinent question: how many of you all think you all are going to keep your men by having a baby?"

Participants in the drug-dependant women focus groups supported that role of baby's father was a barrier to care, as in the following:

"I didn't go for my prenatal care or nothing. I stayed home, I was lazy, wouldn't do nothing. My baby's father sent me through so much stuff, I was like forget it."

Third general theme: staff or provider attitude

The attitude of health care providers and staff was another important issue, although not as pervasive as drug lifestyle or role of baby's father. This code, representing a barrier to prenatal care, was frequently identified in all group types except significant others.

Staff attitude was generally framed such that if staff were friendly, it would motivate care, as in the following from drug dependent women focus groups:

"Thank you. And, how are you? And, Good morning, how did you rest last night? We got to go back to the basics; they need to start taking a group and start sending them out to seminars. Start having these seminars where learning to care, if you're in that field, you got to learn how to care about people, [or] what the hell are you doing with that type of job?"

One participant said:

"When providers find out you use drugs, they treat you bad, i.e., like an addict. [They] put you on the table like you're a piece of meat, it all has to do with, 'oh you've been sent over here from [treatment site]', you know what I'm saying. Addicts, being addicts, under privileged, and you done been through the ringer and you're trying to get your life back into perspective and they treat you like a bunch of crap."

Significant others in the community focus groups also saw staff or provider attitudes as important, as in the following:

"I will come back. But first you have to motivate me to get me in the door. Maybe you're looking for a program, something that teenagers are looking for, whatever gimmick to get me in there."

Homeless women emphasized the complexity of this issue in the following quote:

"...nurses and staff. And they need to advertise it to the community, not just come free for a service, anywhere, you coming free for a service that is a good service that you would receive anywhere else. You need not know it's a free service."

Substance abusing women stated the following:

"In the community they say you better go to the doctor, you know you're suppose to go to the doctor but you don't want to go to the doctor because the doctor is not private anymore. He's got a list and he tells everybody he knows...because there is no one there with that one-on-one kind of treatment. It's just like, yeah your pregnant, get in line, wait your turn."

\section{Discussion}

This study provided an opportunity to listen to perceptions of some of the most vulnerable people in urban settings: the homeless, the substance abusing, and members of high-risk communities. The focus group painted a col- 
lective, rather than individualistic view of health attitudes, beliefs and experiences in the community. The candor of the quotes attests to the ability of the researchers to elicit and be open to whatever remarks participants were willing to contribute. It is important to note that the researchers learned much about what prohibits and what encourages utilization of prenatal care. However, more important is the lesson that utilization of prenatal care must be viewed in context of people's lives, i.e. the complexity of surviving in vulnerable situations overshadows the need for prenatal care. Some issues were more relevant for certain types of groups than others.

This study presents issues that are reported to be barriers to prenatal care, as well as motivators of care. The three pervasive issues were so dominant that they should be considered by any group seeking to provide relevant prenatal care services to vulnerable populations. These issues: drug lifestyle, role of baby's father, and attitudes of health care providers and staff emphasize the importance of developing healthcare policies that meet the perceived needs of the population served. In published literature about barriers to care, influences of drug lifestyles and poor treatment in the system are documented barriers. However, the role of baby's father has not frequently been articulated as either a barrier of motivator. Real creativity is needed to include fathers in development of prenatal care services, as well as in the health care delivery system to provide relevant, easily accessible care. One way that prenatal care should be modeled based on these findings would be to include an emphasis on developing an environment hospitable to individual clients, an alertness to drug dependent lifestyles, and an emphasis on inclusion of the baby's father in every aspect of care. Although drug lifestyles are typically identified as barriers to prenatal care, providers and staff need to be alerted to the notion that occasionally, drug use might also interact with prenatal care to facilitate access to both prenatal care and drug treatment. As, in D.C., there is no mandatory reporting of maternal substance use during pregnancy, the fear of discovery of illicit drug use is not a reason for non participation in prenatal care. Rather the hope of getting into drug treatment facilities may have prompted women to present for prenatal care since drug treatment facilities catering to pregnant women and women with small children are scarce.

\section{Conclusions}

The pervasiveness of drug lifestyle is one that has been only moderately well addressed in current care systems. Inpatient drug treatment is often overcrowded and inaccessible, although women pointed out that pregnancy could break down some of the barriers to drug treatment, which in turn provided access to prenatal care. In outpatient prenatal care settings, it was apparent that not only did drug use interfere with obtaining care, but also, sometimes the outpatient care received was perceived as judgmental, inadequate, or irrelevant for their real need to address substance abuse issues. Designing prenatal care that includes expertise in drug related issues and incorporating drug treatment in care are possible interventions. The provision of more drug treatment facilities that cater to pregnant and post-partum women should be considered an imperative.

The role of baby's father requires a concerted focus. The baby's father as a barrier to be overcome, as well as his usefulness as a motivator or facilitator of care must be considered in the design of prenatal care systems. Fathers can no longer be an observer to care, particularly for vulnerable women. Emphasizing their role in prenatal care may have many benefits, among them: adding to the prenatal care experience, and encouraging stronger families in the future. Separate programs focusing on fathers and expectant fathers that address unique male issues and parenting programs would be a benefit to this community.

In designing prenatal care systems, the importance of health care providers' and staff attitudes cannot be overemphasized. As presented by subjects, what can facilitate care with openness and helpfulness to the most vulnerable can also block care when attitudes are threatening or judgmental. Addressing this issue is not simple. Providers are tasked with emotionally draining work and may have few resources, which may be reflected in their attitudes. As providers and staff gain skill working with vulnerable families, they become qualified for, and move on to less difficult jobs. Each system should evaluate communication patterns with vulnerable women, with an emphasis on providing clear, and non-judgmental communication. Support staff, such as appointment clerks, WIC personnel, and nurses' aids should also be trained to communicate with patients in a respectful way. Clinics providing prenatal care could have occasional peer evaluation of their communication patterns, as well as ombudsmen to function as client advocates, and help them feel more of a part of the system.

As with any qualitative study there are certain limitations [43]. There was no verification of subjects' actual prenatal care experiences. Rather, the information provided by the subjects was considered to be honest and to accurately represent their experiences. Although the goal was to include hard-to-reach women, by definition, the hardest to reach may not have been willing to participate. In spite of these limitations, qualitative methods were appropriate for this study as these methods are superior to quantitative in allowing for contextual meanings of events from personal perspectives [46]. 
In conclusion, to design a prenatal care system that is relevant to the vulnerable people of urban communities will take creativity, thoughtfulness, and sensitivity. There must be frequent interaction with mothers, fathers, and providers. There must be an increased availability and access to drug treatment that is sensitive to pregnant and post-partum women in an urban society. Strategies should be developed to promote understanding of what is included in sensitive care among providers and consumers.

\section{Competing interests}

None declared.

\section{Authors' contributions}

Dr. Milligan, as co-PI of the Barriers, Motivators, and Facilitators of Prenatal Care Protocol, conceived of the study and acted as PI of the focus group project, leading the data collection, analysis, and manuscript preparation and revision. Ms. Wingrove, as Project Officer for NICHD, acted as co-moderator of focus groups, participated in analyzing focus group transcripts, preparing the manuscript, revising the manuscript, formulating the bibliography and advised on budgetary considerations. Dr. Richards arranged for access to drug abusing women and participated in analyzing focus group transcripts. Dr. Rodan arranged for community focus groups and participated in analyzing focus group transcripts. Dr. Monroe-Lord devised the focus group scripts and trained the researchers on focus group facilitation. Ms. Jackson entered all transcripts into Ethnograph and participated in the analysis. Dr. Hatcher arranged for and led the significant other focus groups, participated in the analysis and manuscript preparation. Dr. Harris performed as a focus group moderator, participated in the analysis and manuscript preparation. Dr. Henderson performed as a focus group moderator, participated in the analysis and manuscript preparation. Dr. Johnson, as co-PI of the Barriers, Motivators, and Facilitators of Prenatal Care Protocol participated in the analysis.

\section{All authors read and approved the final manuscript.}

\section{Acknowledgement}

This study was part of the NIH-DC Initiative to Reduce Infant Mortality in Minority Populations in the District of Columbia and was funded by The NIH Office of Research on Minority Health and The National Institute of Child Health and Human Development. The following institutions and investigators participated in the NIH-DC Initiative to Reduce Infant Mortality in Minority Populations in the District of Columbia: The Children's National Medical Center - P. Scheidt (principal investigator); The D.C. Department of Public Health - B. Hatcher (principal investigator); D.C. General Hospital - L. Johnson (principal investigator); Georgetown University Medical Center - K N Sivasubramanian (principal investigator); Howard University - B. Wesley (principal investigator); The University of the District of Columbia - V. Melnick (principal investigator); The Research Triangle Institute - V. Rao (principal investigator); The NICHD - A. Herman (Scientific Coordinator), B. Wingrove (Program Officer). Supported by grants (UI8HD30447, UI8-HD30458, UI8-HD30450, UI8-HD30445, UI8-HD3I9I9, UI8-HD30454, and UI8-HD3 I206) from the NICHD and the NIH ORMH.

\section{References}

I. Mathews T, Curtin M, MacDorman M: Infant Mortality Statistics from the 1998 Period Linked Birth/Infant Death Data Set. U.S. Department of Health and Human Services, CDC, NCHS. National Vital Statistics Reports. 2000, 48( ( 2): I-9

2. U.S. Department of Health and Human Services: Healthy People 2000: National Health Promotion and Disease Prevention Objectives. Washington, D.C., HHS, Public Health Service. 1991

3. U.S. Department of Health and Human Services: Tracking Healthy People 20 I0. Washington, D.C., HHS, Public Health Service. 2000

4. D.C. Department of Health: State Center for Health Statistics. Washington, D.C. 1997

5. American College of Obstetricians and Gynocologists: Standards for Obstetric-Gynecologic Services. Chicago, III, American College of Obstetricians and Gynecologists. 1994

6. Nguyen $\mathrm{TH}$, Chongsuvivatwong $\mathrm{V}$ : Impact of prenatal care on perinatal mortality. SWHC 1997, I:55-6I

7. Liu G: Birth outcomes and the effectiveness of prenatal care. HRS: Health Service Research 1998, 32:805-823

8. Frick K, Lantz P: Commentary: How well do we understand the relationship between prenatal care and birth weight? HRS: Health Service Research 1999, 34: 1063-1071

9. Liu G: On the issues of the effectiveness of prenatal care: A reply. HRS: Health Service Research 1999, 34: 1074-1082

10. Rosenberg K: Benefits and limitations of prenatal care. JAMA 1998, 280:2072

II. Rooks J: Benefits and limitations of prenatal care. JAMA 1998 , 280:2072-2073

12. Martin J, Hamilton B, Ventura Births M: Preliminary Data for 2000. Hyattsville, Maryland, Department of Health and Human Services, CDC, NCHS. National Vital Statistics Reports. 200I, 49(5): 15

13. Ahmed FP, McRae JA, Ahmed NM: Factors Associated with Not Receiving Adequate Prenatal Care in an Urban Black Population: Program Planning Implications. SWHC 1990, 14:107123

14. Brown SS: Prenatal Care Reaching Mothers, Reaching Infants. Washington, D.C. National Academy Press 1988

15. Campbell JD, Mitchell P, Stanford JB, Ewigman BG: Validating a Model Developed to Predict Prenatal Care Utilization. JFP 1995, 41:457-464

16. Freda MC, Chazotte C, Youchah J: What Do We Know About How to Enroll and Retain Pregnant Drug Users in Prenatal Care? Journal of Women's Health 1995, 4:55-63

17. Bluestein DM, Rutledge CM: Psychosocial Determinants of Late Prenatal Care: The Health Belief Model. Family Medicine 1993, 25(4):269-272

18. Goldenberg R, Patterson E, Freese M: Maternal Demographic, Situational and Psychosocial Factors and Their Relationship to Enrollment in Prenatal Care: A Review of the Literature. Women \& Health 1992, 19(2/3):|33-15|

19. Joyce K, Diffenbacher G, Grene J, Sorokin Y: Internal and External Barriers to Obtaining Prenatal Care. SWHC 1983, 9:89-96

20. Issel L: Women's perceptions of outcomes of prenatal care management. Birth 2000, 27:2

21. Lee SH, Grubbs LM: Pregnant Teenagers' Reasons for Seeking or Delaying Prenatal Care. Clinical Nursing Research 1995, 4:38-49

22. Napravnik S, Royce R, Walter E, Lim W: Infected Women and Prenatal Care Utilization: Barriers and Facilitators. AIDS Patient Care and STDs 2000, 14:4I I-420

23. Laveist TA, Keith VM, Gutierrez ML: Black/White Differences in Prenatal Care Utilization: An Assessment of Predisposing and Enabling Factors. HRS: Health Service Research 1995, 30:43-58

24. Kroelinger C, Oths K: Partner Support and Pregnancy Wantedness. Birth 2000, 27:1 I2-119

25. Delgado-Rodriguez M, Gomez-Olmedo M, Bueno-Cavanillas A, Galvez-Vargas R: Unplanned pregnancy as a major determinant in inadequate use of prenatal care. Preventive Medicine 1997, 26:834-838

26. Mayer J: Unintended childbearing, maternal beliefs, and delay of prenatal care. Birth 1997, 24:247-250

27. Reis J, Mills-Thomas B, Robinson D, Anderson V: An Inner-City Community's Perspective on Infant Mortality and Prenatal Care. PHN 1992, 9(4):248-256

28. Long C, Curry M: Living in two worlds: Native America Women and Prenatal Care. Health Care for Women International 1998, 19:205-215 
29. Wieman C, Berenson A, Pino L, McCombs S: Factors associated with adolescents' risk for late entry into prenatal care. FPP 1997, 29:273-276

30. Kalmus D, Fennelly K: Barriers to Prenatal Care Among Low Income Women in New York City. FPP 1990, 22(5):21 5 -23 I

31. Patterson ET, Freese MP, Goldenberg RL: Seeking Safe Passage: Utilizing Health Care During Pregnancy. JNS I990, 22(I):2731

32. Melnikow J, Alemagno SA, Rottman C, Zyzanski SJ: Characteristics of Inner-City Women Giving Birth with Little or No Prenatal Care: A Case-Control Study. JFP I991, 32(3):283-288

33. Meikle SFMM, Orleans MP, Leff MMM, Shain RP, Gibbs RSM: Women's Reasons for Not Seeking Prenatal Care: Racial and Ethnic Factors. Birth 1995, 22:81-86

34. Ensign J, Panke A: Barriers and bridges to care: voices of homeless female adolescent youth in Seattle, Washington. Journal of Advanced Nursing 2002, 37:166-172

35. Ensign J, Santelli J: Shelter-based homeless youth - Health and access to care. Archives of Pediatrics \& Adolescent Medicine 1997, 1 81:817-823

36. Proctor $\mathrm{S}$ : What determines quality in maternity care? Comparing the perceptions of childbearing women and midwifes. Birth 1998, 25:85-93

37. Dobie S, Hart L, Fordyce M, Andrilla C, Rosenblatt R: Obstetric care and payment sources: do low-risk Medicaid women get less care? American Journal of Public Health 1998, 88:5I-56

38. Gifford B: Obstetricians' receptiveness to teen prenatal patients who are Medicaid recipients. HRS: Health Service Research 1997, 32:265-282

39. McCourt C, Pearce A: Does continuity of care matter to women from minority ethnic groups? Midwifery (2000) 2000, I 6: I45154

40. Shulman L: The skills of helping individuals, families, groups and communities. Itasca, Illinois F.E. Peacock Press 2002

4I. Lia-Hoagberg B, Rode P, Skovholt CJ, Oberg CN, Berg C, Mullett S, et al: Barriers and Motivators to Prenatal Care Among LowIncome Women. Soc Sci Med 1990, 30(4):487-495

42. Johnson L, Yanca S: Social work practice: a generalist approach. Boston, MA 2002

43. Denzin N, Lincoln Y: Handbook of qualitative research 2000

44. Asbury: Overview of focus group research. Qualitative Health Research 1990, 5:4|4-420

45. Patton M: Qualitative Evaluation and Research Methods Newbury Park, CA: Sage Publications, inc. 1990

46. Miles M, Huberman A: Qualitative Data Analysis Thousand Oaks, CA Sage Publications, Inc 1994

47. Seidel J, Friese S, Leonard D: The Ethnograph. Qualis Research Associates. 1995

48. Milligan R, Hoffart R: The Ethnograph Cv3.0. Advanced Nursing Research (special interest Newsletter) 1991 September

49. Sword W: A socio-ecological approach to understanding barriers to prenatal care for women of low income. Journal of Advanced Nursing 1999, 29: I 170- I I 77

50. Koch T: Establishing rigor in qualitative research: the decision trail. Journal of Advanced Nursing 1994, 19:976-986

\section{Pre-publication history}

The pre-publication history for this paper can be accessed here:

http://www.biomedcentral.com/1471-2458/2/25/prepub

\footnotetext{
Publish with BioMed Central and every scientist can read your work free of charge

"BioMedcentral will be the most significant development for disseminating the results of biomedical research in our lifetime."

Paul Nurse, Director-General, Imperial Cancer Research Fund

Publish with BMC and your research papers will be:

- available free of charge to the entire biomedical community

- peer reviewed and published immediately upon acceptance

- cited in PubMed and archived on PubMed Central

- yours - you keep the copyright

Submit your manuscript here: BioMedcentral.com

http://www.biomedcentral.com/manuscript/
} 